\title{
EVALUATION OF INDICATIONS OF COLOSTOMY AND STUDY ITS COMPLICATION AT SURGERY DEPARTMENT OF ANMMCH, GAYA, BIHAR
}

\section{Surgery}

Dr. Kishore Kumar M.S. (Gen. Surg.), Associate Professor, Department of surgery, Anugrah Narayan Sinha Magadh Medical College and Hospital, Gaya, Bihar.

Dr. Shiv Narayan Singh*

\section{Dr. Shri Krishna} Ranjan

M.S. (Gen. Surg.), Assistant Professor, Department of surgery, Anugrah Narayan Magadh Medical College and Hospital, Gaya, Bihar. *Corresponding Author

M.S. (Gen. Surg.), Associate Professor, Department of surgery, Anugrah Narayan Magadh Medical College and Hospital, Gaya, Bihar.

\section{Dr. Debarshi Jana}

A.J.C. Bose Road, Kolkata-700020, West Bengal, India

\section{ABSTRACT}

Objective: To evaluate the indications of colostomy and study its complication.

Methodology: This prospective study was carried out in department of general surgery, A. N. Magadh Medical College and Hospital, Gaya, Bihar from July 2016 to June 2019 A total 118 patients of colostomies done either elective or emergency setting for any cause was included in this study. Results: out of total 118 patients, Males ( $\mathrm{n}=87$ out of $74 \%$ were commonly affected then female $(\mathrm{n}=31$ out of 118$) 26 \%$. Maximum number of cases were in 51 to 60 age group $(\mathrm{n}=35$ out of 118$) 30 \%$. The most common indication for colostomy formation was carcinoma ( $\mathrm{n}=55,46.6 \%)$, followed by intestinal obstruction $(n=28,23.7 \%)$. In colostomy patients total $n=57$ complications were observed in 54 patients that is $46.4 \%$ of patients. In our study the complication were reported as Local sepsis $25 \%$, Prolapse $7 \%$, Retraction $4 \%$, Necrosis $4 \%$, Parastomal hernia $1.6 \%$, Stenosis $1.6 \%$, Intestinal obstruction $1.6 \%$, Bleeding $1.6 \%$.

Conclusion: The carcinoma of the colon and rectum is the most common indication for the colostomy. The local sepsis is the most common complication.

\section{KEYWORDS}

\section{INTRODUCTION}

The first surgical stoma was created more than 200 years ago. The word stoma comes from the Greek word meaning mouth or opening. An intestinal stoma is an opening of the intestine on anterior abdominal wall made surgically.

Littre of Paris was the first to make a ventral colostomy in 1970 for a boy with imperforate anus.

Stomas are used to divert the faecal stream away from distal bowel in order to allow a distal anastomosis to heal as well as to relieve obstruction in emergency situation. Various indication for which intestinal stomas are formed Ulcerative colitis, bowel obstruction, cancer of colon and rectum, crohn's disease, congenital bowel defects, uncontrolled bleeding from large intestine, injury to the intestinal tract, inflammatory bowel disease, ischemic bowel disease, carcinoma of urinary bladder and spinal cord injury.

Stomas though lives saving procedure, it carries significant number of complication and cause social isolation and significant reduction in quality of life. The earliest stomas were actually unintentional ones, enterocutaneous fistula resulting from penetrating abdominal injuries or complication of intestinal disease such as incarcerated hernia.

Patients undergoing stoma formation are at risk of developing a wide range of complication following surgery. There are many factors suggested to predispose to stoma complication like high body mass index, inflammatory bowel disease, use of steroids and immunosuppressant drugs, diabetes mellitus, old ages, emergency surgery, surgical techniques and surgeons experience.

\section{Aim of the Study}

The aim of our study is to evaluate indications of colostomy and study its complication.

\section{Materials and Methods}

This prospective study was carried out in Department of General Surgery, Anugrah Narayan Magadh Medical College and Hospital, Gaya, Bihar from July 2016 to June 2019.
A total 118 patients of colostomies done either elective or emergency setting for any cause was included in this study. Data was collected from patient's record maintained by department of surgery from operated notes and patients case records. These cases were studied to evaluate indication, types and complication of colostomies.

\section{Inclusion Criteria}

1) All patient male and female between 1-70 years

2) All emergency and elective cases undergoing intestinal stoma construction

Exclusion Criteria

1) Patients undergoing urinary stoma construction

2) Patients undergoing stoma construction as indication for gynaecological disorders

Results

Table 1: Age Distribution

\begin{tabular}{|c|c|c|}
\hline Age group (years) & Frequency & Percent \\
\hline $1-10$ & 12 & 10 \\
\hline $11-20$ & 9 & 7.6 \\
\hline $21-30$ & 13 & 11 \\
\hline $31-40$ & 24 & 20.3 \\
\hline $41-50$ & 11 & 9.3 \\
\hline $51-60$ & 35 & 30 \\
\hline$>60$ & 14 & 11.8 \\
\hline TOTAL & 118 & 100 \\
\hline
\end{tabular}

In our study Maximum number of cases were in 51 to 60 age group $(n=35$ out of 118$) 30 \%$ followed by 31 to 40 age group $(n=24)$ table 1 .

Table 2: Sex distribution

\begin{tabular}{|c|c|c|}
\hline Sex & Frequency & Percent \\
\hline Female & 31 & 26 \\
\hline Male & 87 & 74 \\
\hline Total & 118 & 100 \\
\hline
\end{tabular}

In our study Males ( $\mathrm{n}=87$ out of 118 ) were commonly affected then female $(n=31$ out of 118$) 26 \%$ table 2 . 
Table 3: Elective Vs emergency

\begin{tabular}{|c|c|}
\hline Elective & Emergency \\
\hline 13 & 105 \\
\hline $11 \%$ & $89 \%$ \\
\hline
\end{tabular}

In our study $105(89 \%)$ stomas are made in emergency setting and in $13(11 \%)$ were made in routine table 3 .

Table 4: Indications

\begin{tabular}{|l|c|c|}
\hline \multicolumn{1}{|c|}{ Indications } & Number of stomas & Percentage \\
\hline Carcinoma colon and rectum & 55 & 46.6 \\
\hline Intestinal obstruction & 28 & 23.7 \\
\hline Abdominal trauma & 16 & 13.6 \\
\hline Ano rectal malformation & 10 & 8.5 \\
\hline Sigmoid volvulus & 4 & 3.4 \\
\hline Hirschprung disease & 3 & 2.5 \\
\hline High fistula in ano & 2 & 1.7 \\
\hline TOTAL & 118 & 1 oo \\
\hline
\end{tabular}

In our study the most common indication for colostomy formation was carcinoma $(n=55,46.6 \%)$, followed by intestinal obstruction $(n=28$, $23.7 \%)$ followed by abdominal trauma $(n=16,13.6 \%)$, followed by anorectal malformation $(\mathrm{n}=10,8.5 \%)$, followed by sigmoid volvulus $(\mathrm{n}=4,3.4 \%)$ followed by hirschprung disease $(\mathrm{n}=3,2.5 \%)$, followed by high fistula in ano(n=2,1.7\%) table 4 .

Table 5: Types of stoma

\begin{tabular}{|l|c|c|}
\hline \multicolumn{1}{|c|}{ Procedure } & Numbers & Percent \\
\hline Sigmoid colostomy & 78 & 66 \\
\hline Loop colostomy & 33 & 28 \\
\hline End colostomy & 7 & 6 \\
\hline TOTAL & 118 & 100 \\
\hline
\end{tabular}

In our study the most commonly performed colostomy is the sigmoid colostomy $66 \%$, followed by the loop colostomy $28 \%$ and least is end colostomy $6 \%$ table 5 .

Table 6: Complication

\begin{tabular}{|l|c|c|}
\hline Complication & Number & Percent \\
\hline Local sepsis & 30 & 25 \\
\hline Prolapse & 9 & 7 \\
\hline Retraction & 5 & 4 \\
\hline Necrosis & 5 & 4 \\
\hline Parastomal hernia & 2 & 1.6 \\
\hline Stenosis & 2 & 1.6 \\
\hline Intestinal obstruction & 2 & 1.6 \\
\hline Bleeding & 2 & 1.6 \\
\hline Electrolyte imbalance & 0 & 0 \\
\hline & 57 & 46.4 \\
\hline
\end{tabular}

In colostomy patients total $\mathrm{n}=57$ complications were observed in 54 patients that is $46.4 \%$ of patients. In our study the complication were reported as Local sepsis 25\%, Prolapse 7\%, Retraction 4\%, Necrosis $4 \%$, Parastomal hernia $1.6 \%$, Stenosis $1.6 \%$, Intestinal obstruction $1.6 \%$, Bleeding $1.6 \%$ table 6 .

\section{DISCUSSION}

Taking into account the various data from literature and comparing it with present series a few interesting fact is come into lime light.

Maximum number of cases were in 51 to 60 age group ( $\mathrm{n}=35$ out of 118) $30 \%$. Males ( $\mathrm{n}=87$ out of 118 ) were commonly affected then female ( $\mathrm{n}=31$ out of 118$) 26 \%$. While study conducted by P. Sumathi et al. showed maximum number of patients was in the age group of 55 to 65 year $(n=32$ out of 50$)$ and males $(n=36$ out of 50$)$ are more commonly affected than females $(n=14)$. While study conducted by $\mathrm{Ahmad} Z$ et al. showed out of 100,70 were males and 30 were females. The mean age group was $50.5 \pm 29.01$ year with a range of 12 to 85 year.

In our study $105(89 \%)$ stomas are made in emergency setting and in $13(11 \%)$ were made in routine. While in study conducted by Ahmad Z et al. showed 97 stomas were made in emergency and 3 stoma were made in routine.

The most common indication for colostomy formation was carcinoma $(n=55,46.6 \%)$, followed by intestinal obstruction $(n=28,23.7 \%)$ followed by abdominal trauma $(n=16,13.6 \%)$, followed by anorectal malformation $(n=10,8.5 \%)$, followed by sigmoid volvulus $(n=4$, $3.4 \%$ ) followed by hirschprung disease $(\mathrm{n}=3,2.5 \%)$, followed by high fistula in ano(n=2,1.7\%). Study conducted by P.Sumathi et al. showed the most common indication for stoma were carcinoma followed by abdominal trauma.

In our study the most commonly performed colostomy is the sigmoid colostomy $66 \%$, followed by the loop colostomy $28 \%$ and least is end colostomy $6 \%$.while study conducted by P. Sumathi et al. showed the most common stoma created was colostomy $n=41$ out of 50 . Same study showed total 41 patients underwent colostomy formation of which 22 were end colostomy and 19 were transverse loop colostomy. While study conducted by Ahmad Z et al. showed, the most common stoma was loop ileostomy followed by sigmoid colostomy, followed by transverse loop colostomy with most of them being formed in males $76 \%{ }^{10}$. Similar in a study by Shah JN et al. loop ileostomy was the most common stoma formed (70\%) followed by loop colostomy (17\%). Ileostomy accounted for $70 \%$ stomas in another study by Ghazi MA et al. followed by colostomy in $30 \%$. In a study by Safirullah et al. loopileostomy was formed in $43 \%$ cases and loop colostomy in $17.4 \%$ of cases.

In colostomy patients total $\mathrm{n}=57$ complications were observed in 54 patients that is $46.4 \%$ of patients. In our study the complication were reported as Local sepsis 25\%, Prolapse 7\%, Retraction 4\%, Necrosis $4 \%$, Parastomal hernia $1.6 \%$, Stenosis $1.6 \%$, Intestinal obstruction $1.6 \%$, Bleeding $1.6 \%$. The local sepsis complication werecommonly seen in study conducted by P. Sumathi et al. in the form of chemical dermatitis and folliculitis occur in patients undergone end colostomy. In allof them, major was alack of proper seal around stoma and stoma bag. All of them were treated by applying a colostomy paste which formed a protective barrier over the skin. Use of a skin sealent with a copolymer or plasticizing agent without alcohol provide a thin protective film on the skin surface helps prevent skin stripping of the epidermis during adhesive removal and as a moisture barrier.

The most common complication reported in Ahmad $\mathrm{Z}$ et al. was peristomal skin irritation and erythema $(36 \%)$ followed by laparotomy wound infection $(13.4 \%)$ and peristomal skin infection, abscess formation and fistula formation $(8.1 \%)$.

A study by Ratliff et al. has shown peristomal irritation in 53\% cases, while Pearl et al. showed peristomal erythema as the most common complication in $42 \%$. Ambreenmuneer reported skin excoriation in $18 \%$ cases. Safirullah et al. reported skin erythema in $12 \%$ followed by prolapse $6 \%$ and retraction $4 \%$.

In study conducted by P. Sumathi et al. showed loop colostomy tends to prolapse more than colostomy and proximal more than distal. Then necrosis was observed in $5 \%$ of patients and found in immediate postoperative period. It requires laparotomy and revision of stoma.

\section{CONCLUSION}

Although stomal complication is a novel risk for mortality, it is acknowledged that others established prognostic indicators hold stronger influence. As such age, urgency of surgery and diagnosis are found to influence morbidity and mortality.

\section{REFERENCES}

1. Ahmad Zetal. Int JRes Med Sci. 2013 Nov;1(4):536-540.

2. AmbreenMuneer, A. RazaqueShaikh, GulsanAra Shah, Ali Qureshi, Liaquat University of Medical \& Health Sciences, Jamshoro, Sind Pakistan. World Applied Sciences Journal 2007; 2(3): 190-193

3. Arumugam PJ, Bevan L, Macdonald L, Watkins AJ, Morgan AR, Beynon J et al. A prospective audit of stomas - analysis of risk factors and complications and their management. Colorectal Dis 2003;5:49-52.

4. Crohn's and Colitis Foundation of America. 386 Park Ave. S. 17thFloor. New York. NY 10016.(800) 826-0826.

5. Jay N Shah, N. Subedi, S. Maharjan. Stoma Reversal, a hospital based study of 32 cases. Internet journal of surgery $2009 ; 22(1)$

6. Kaider-Person O Person B, Wexner SD Complications of construction and closure of temporary loop ileostomy. JAm CollSurg 2005;201:759-73.

7. Khalid AM, Irshad W. Surgical history of intestinal obstruction. Specialist 1991; 8 (1) 55-60.

8. MeGrath A, Porrett T, Heyman B. Parastomal hernia: an exploration of the risk factor and the implication. BrJ Nurs 2006;12;317-21.

9. Muhammad Ahmad Ghazi, Amir RiazBhutia, Hafiz Muhammad, AsifMaqbool, NaumanDawood, NasirMahmood. The trends and outcome of stoma procedures in abdominal surgery, Pak Journal of Med and Health Sciences 2009;3(2):106

10. P Sumathi M.S et al. A clinical study of intestinal stomas, their complications and management. IOSR-JDMS, volume 15 , issue 12 ver. 1 (December. 2016), pp 39-42.

11. Pearl RK, Prasad ML, Orsay CP, Abcarian H, Tan AB, Melze MT Early loca complications from intestinal stomas, Asch Surg 1985; 120 (10):1145-47.

12. Ratliff, Catherino R. Journal of wound, Ostomy\& Continence Nursing 2010;37(5):505 
510.

13. Safirullah, Mumtaz N, Jan MA, Ahmed S. Complications of intestinal stomas. J Postgrad Med Inst. 2005;19(4):407-11.

14. Saunders RN, Hemingway D. Intestinal Stomas. SurgInt 2005;71:44-7.

15. Taylor P. An introduction to stomas: reasons for their formation. Nurs Times $2005 ; 101: 63-4$. 